\title{
Spectrum of benign breast diseases \& role of self breast examination: a medical college experience in Madhya Pradesh
}

\author{
Brahmachari S ${ }^{1}$, Sharma S ${ }^{2}$, Pandey $A^{3}$ \\ ${ }^{1}$ Dr Swagata Brahmachari, Associate Professor, ${ }^{2}$ Dr Shrikant Sharma, Associate Professor, ${ }^{3}$ Dr Anubha Pandey Resident, \\ Department of Surgery, L.N. Medical College \& J.K. Hospital, Kolar Road, Bhopal, MP, India
}

Address for Correspondence: Dr Swagata Brahmachari, Associate Professor, Department of Surgery L.N. Medical College \& J.K. Hospital, Kolar Road, Bhopal.

\begin{abstract}
Objectives: The aim of the study to create awareness of self breast examination in and around a medical college hospital, to see how it changes the scenario and to study the clinic-pathological study of breast diseases in these patients. Methodology: Cross-sectional study was carried out in a medical college \& hospital. Females were counseled and taught about the importance and method of self breast examination. Then patients of breast diseases who attended the surgery outdoor clinics and gave detailed clinical history were delineated and findings were recorded in a standard proforma. Results: There was more than $300 \%$ increase in the number of patients after the self breast awareness campaign which is great success. $66 \%$ patients were found to have a significant pathology. Among benign breast diseases, fibroadenoma was the most common lesion constituting (68.12\%) cases. Benign breast diseases are commonly seen in younger age group and usually presented with either breast lumps or nodularity. Conclusion: Awareness spread via counseling and teaching classes was very useful. Self Breast Examination being a screening tool is a good measure. Further evaluation is required by other methods to finally reach to a definitive diagnosis and to further plan treatment.
\end{abstract}

Key words: Benign Breast Diseases, Fibroadenoma, Fibroadenosis, self breast examination

\section{Introduction}

Benign swellings constitute one of the commonest of diseases affecting the female breast [1]. The rate of benign disease of malignancy is 10:1. In the female, from puberty to death, the breast is subjected to physiological changes related to the menstrual cycle, pregnancy, lactation and menopause. Clinically defined benign breast symptoms tend to occur in $50 \%$ of women at some point at their lifetime [2].

Proper intervention through training programmes at regular time interval has global influence on breast diseases mortality. Training programmes not only increase knowledge and awareness among health care professionals but also develops sense of responsibility which reflects in their attitude and practices. Since everyone's attention was drawn towards cancer, the main area of investigation was assessment of pre-

Manuscript received $10^{\text {th }}$ November 2016

Reviewed: $18^{\text {th }}$ November 2016

Author Corrected: $28^{\text {th }}$ November 2016

Accepted for Publication $06^{\text {th }}$ December 2016 malignant potential of fibrocystic diseases which yielded largely variable outcomes. However the main age of developing benign breast disease is $15-20$ years less than that of breast cancers $[3,4,5]$.

The main problem from the patient's point of view in the intense anxiety associated with any symptoms related to the breast is due to the fear of cancer. Anxiety aside, serious cosmetic problems may result from repeated small biopsies or removal of breast quadrants in an attempt to search for small mammographic abnormalities. At present surgeons main concern is to create awareness via SBE and to exclude the dreaded carcinoma while treating benign breast lesions and alleviate the fear of carcinoma $[4,6]$.

\section{Methodology}

Study was conducted in the department of surgery in collaboration with the department of obstetrics and gynecology. Two groups were made, Group A and 
Group B. Group A consisted of the pre education era in which people were attending regular breast clinic in surgical and gynae OPD‘s without any knowledge about self breast examination. In Group B those patients who were made aware by various education programmes were kept and then the data was compared with that of the pre-education era.

Patients were taught about breast self examination via classes, charts, awareness campaigns etc. This study was conducted for a period of 2 years from October 2014 to October 2016. Quality BSE includes the use of proper techniques (massaging search pattern, use of finger pads, and firm pressure) and complete coverage of the breast with proper positioning of the body. Motivation to continue BSE is dependent on providing personalized instruction and periodic reinforcement. Accordingly, the training involved an initial BSE instruction class, which included individual practice, two waves of structured reinforcement activities, regular BSE practice observed by medical workers, handouts for factory medical workers, and reminder posters.

This approach was designed to instill performance of proper BSE technique, to inform women about the need to practice BSE, to identify barriers to practice and how to overcome them, and to encourage women to consider $\mathrm{BSE}$ a routine health practice.

Changes in the breast that may be indicative of cancer

- Change in the outline, shape, or size of the breast

- Puckering or dimpling of the skin

- Any new discrete lump

- Asymmetrical nodularity present early in menstrual cycle, persistent

- Unusual pain or discomfort that is different from normal, particularly if new, persistent, and localised

- Discharge from the nipple that is new, serous, or bloody

- Persistent single duct discharge

- Nipple retraction or distortion

\section{Results}

There was a vast difference in awareness and number of patients presenting to OPD in the pre and post teaching of self breast examination era. It was seen that there were 3990 patients who attended breast clinic in 2015 whereas there were only 1300 patients in 2014.This means that there was more than 300 percent increase in the number of patients after the self breast awareness campaign which is great success. Amongst all patients who reported after getting educated about breast diseases $66 \%$ were found to have a significant pathology .

Among benign breast diseases, fibroadenoma was the most common lesion constituting (68.12\%) cases in our study. Fibroadenosis (presently termed fibrocystic disease) was the second most common lesion constituting (20.30\%) of all cases. Benign breast diseases are commonly seen in younger age group and usually presented with either breast lumps or nodularity, breast pain and nipple discharge of long duration

\section{Figure 1: Distribution of study population according to age}

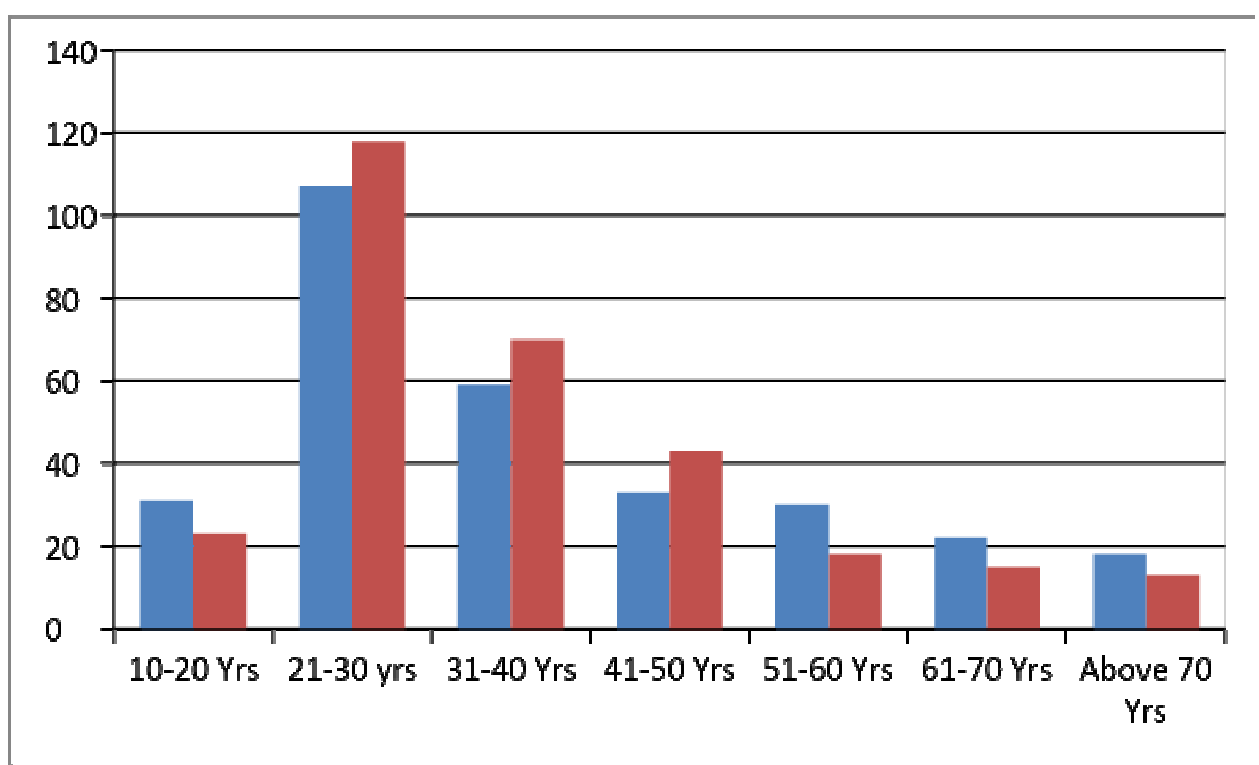


This chart shows that max incidence is found in middle age groups i.e.20-40 years

Figure 2: Patients attending Breast clinic in pre education (2014) and post education (2015) era

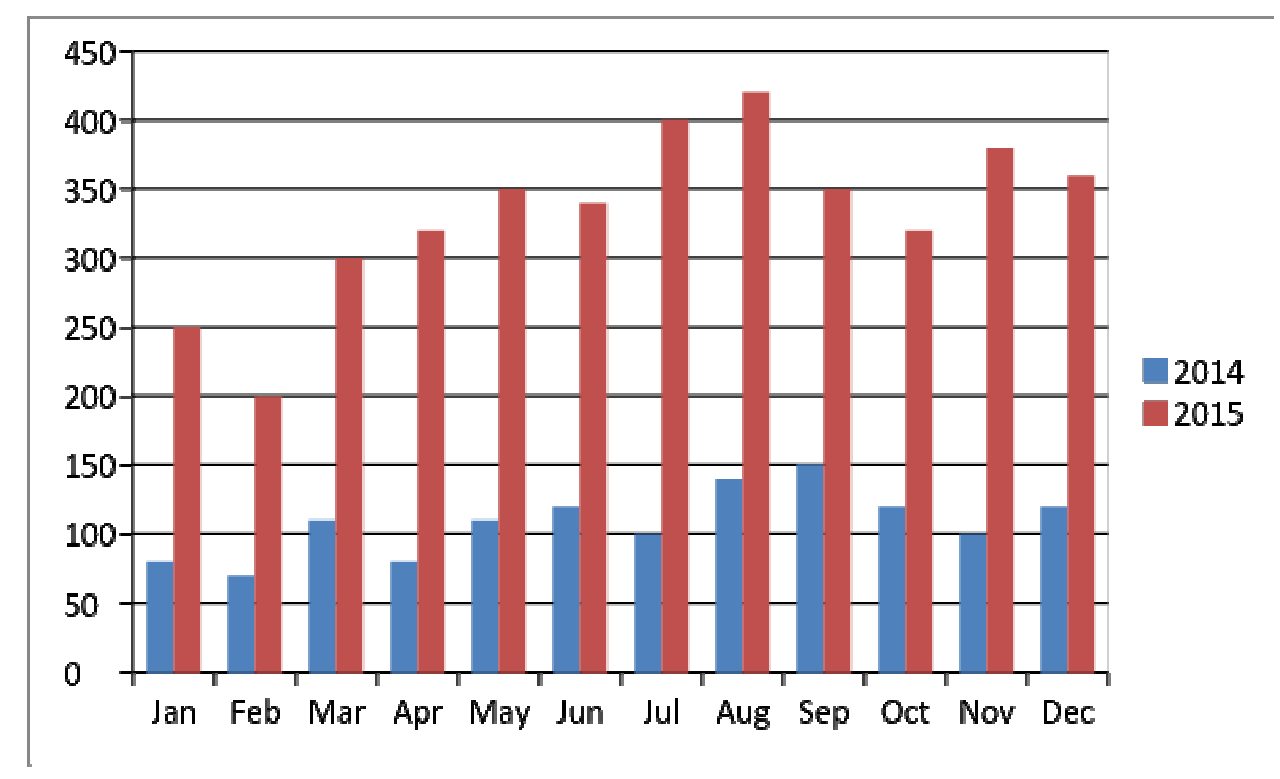

There is a study rise in no. of patients attending breast clinic in all months.

Table 3: Distribution of breast lesions according to diagnosis

\begin{tabular}{|c|c|}
\hline C1- INADEQUATE SAMPLES & $4(1.39 \%)$ \\
\hline C2- BENIGN LESIONS & $230(76.66 \%)$ \\
\hline $\begin{array}{l}\text { Infam matory breast lesions } \\
\text { Breast abcess } \\
\text { Granulomatous mastitis }\end{array}$ & $38(12.6 \%)$ \\
\hline Benign oystic lesions & $31(10.33 \%)$ \\
\hline Fibrocystic changes & $23(7.67 \%)$ \\
\hline Galactocele & $4(1.33 \%)$ \\
\hline Duct ectasia & $2(0.66 \%)$ \\
\hline Fibroadenoma & $122(40.66 \%)$ \\
\hline Benign Phyllodes tumour & $2(0.66 \%)$ \\
\hline Miscellaneous & $8(2-33 \%)$ \\
\hline CO-ATYPIA PROBAELY BENIGN & $4(1.33 \%)$ \\
\hline CA- SUSPICIOUS OF MALIG NANCY & $6(29)$ \\
\hline C5-MALIGNANT LESIONS & $56(18.66 \%)$ \\
\hline
\end{tabular}

Triple assessment is widely accepted as reliable techniques in the initial evaluation of palpable breast lumps. In the present study, $76.66 \%$ were benign cases. Fibroadenoma was the most frequently diagnosed lesion on FNA with maximum patients between 21-30 years. Among all four quadrants, superolateral quadrant was the most common quadrant for breast lesions in the present study (52.33\%).

Statistical analysis- The two-tailed $\mathrm{P}$ value was taken as the criteria to calculate significance. Comparison between various pre-test and post-test values $\mathrm{P}$ value and statistical significance: The two-tailed $\mathrm{P}$ value is less than 0.0001 was considered significant. 
criteria, this

difference is

considered to be extremely statistically significant.

\section{Discussion}

Knowledge and behaviors of female health care workers concerning breast cancer is relatively poor and it needs to be improved. Considering the role that health care workers may play in communicating health behaviors to the general public, planning health education interventions for this group of females is essential. The role of routine self examination of the breasts according to a set technique remains less practiced.

At least 15 retrospective studies have been completed. These studies related the self reported practice of regular breast self examination before the development of breast cancer, or the discovery of breast cancer by self. Eight of these studies showed somewhat more favorably staged tumors at diagnosis in women who claimed to have performed self examination compared with those who did not. Three studies showed a survival advantage in women who performed self examination. The increase in survival seen, for example, may possibly reflect only advancement of diagnosis. Also, it is by no means easy to define retrospectively what constitutes breast self examination [6].

When analyzed by age, breast self examination leads to more lumps being detected in younger women than in older women. This is not surprising as breast lumps are more common in younger women, whose breasts are subject to the fluctuating hormone levels of the menstrual cycle.

Only a few of these lumps in younger women, however, are malignant. In postmenopausal women the likelihood of a lump being malignant is much higher. Therefore younger women practicing breast self examination may have a less favorable balance of potential risks versus benefits. This is similar to the findings of our study in which maximum age incidence is found in middle age [6].

Regular practice of this technique can in itself cause considerable anxiety in some women because of the possibility that they will eventually find something suspicious. Most authorities have suggested that monthly examination is appropriate, but there is no evidence about the advantages of this arbitrarily chosen frequency, which was based on the menstrual cycle despite the fact that most women who develop breast cancer are postmenopausal $[7,8]$
Clinical examination, mammography or sonography and FNAC [triple assessment] is widely accepted as a reliable technique in the initial evaluation of palpable breast lumps. In the present study, $76.66 \%$ were benign cases. Thomas et al studied 1533 breast masses on FNAC and found that $70.4 \%$ cases were benign. Similarly, Baxter et al studied 757 cases on FNAC and found that maximum number of cases were benign $[9,10,11]$.

Fibroadenoma was the most frequently diagnosed lesion on FNAC with maximum patients between 21-30 years. Shukla HS et al also documented fibroadenoma as the most common benign lesion (71.3\%) in their study [7]. Among all four quadrants, superolateral quadrant was the most common quadrant for breast lesions in the present study (52.33\%). Agarwal G et al [5] and Mackinnon WB et al [9] also observed upper and outer quadrant as the commonest site. In the present study, 56 cases were positive for malignancy $(18.6 \%)$ with maximum incidence of ductal carcinoma (NOS) was found in 41-50 years (16 cases) with a mean age of 43.24 yrs.

Foster Jr RS et al determined the relation between breast self-examination performance and the clinical and pathological stage of breast cancer at first diagnosis, they studied 335 patients with breast cancer. Approximately one fourth of the patients reported that they had been practicing monthly breast selfexamination, and half that they had never practiced breast self-examination. More frequent performance of breast self-examination was associated with more favorable clinical stage and fewer axillary-lymph-node metastases on histologic examination. These data associating more favorable clinical and pathological stages of breast cancer with more frequent breast selfexamination need to be extended by determination of the survival rates of the various self-examination groups [12].

Haji-Mahmoodi M, Montazeri A et al did a crosssectional study to examine the knowledge of breast cancer, attitudes toward breast self-examination (BSE), and practice of BSE among a sample of female health care workers in Tehran, Iran. Using a purposed questionnaire, a total of 410 women from seven health centers completed the questionnaire. The mean age of 
the respondents was 32.9 years $(\mathrm{SD}=9.5)$, most $(58 \%)$ were married, and family history of breast cancer was reported by $11 \%$. Seventy-five percent of the women knew about breast cancer prevalence, but only $27 \%$ knew that breast pain is not a symptom of breast cancer. Although $73 \%$ of women did know that contact with a relative with breast cancer could not lead to development of breast cancer, the respondents' knowledge of risk factors of breast cancer was not satisfactory. With regard to women's attitudes toward BSE, the majority believed that it is not difficult and time consuming or troublesome $(63 \%$ and $72 \%$, respectively). Sixty-three percent of the respondents claimed that they know how to examine their breasts, but only $6 \%$ performed BSE monthly. The practice of BSE was significantly associated with age $(p=0.01)$, the level of education $(p<0.0001)$, personal history of breast problems $(p<0.0001)$, and knowledge of how to examine the breasts $(p<0.0001)$. The study findings are in consensus with our study that the knowledge and behaviors of female health care workers concerning breast cancer is relatively poor and it needs to be improved. Considering the role that health care workers may play in communicating health behaviors to the general public, planning health education interventions for this group of females is essential [13].

Austoker J. did breast screening by mammography and showed that it reduces mortality from breast cancer in women aged 50 and over. An NHS breast screening programme has been in operation in the United Kingdom since 1988. Its aim is to reduce mortality from breast cancer by $25 \%$ in the population of women invited to be screened. Primary care teams have an important part to play in encouraging women to attend for screening and in providing information, advice, and reassurance at all stages of the screening process. Mammography is costly and not available freely but BSE is inexpensive. To date, routine breast self examination has been shown to be an effective method of screening for breast cancer and should therefore be promoted as a primary screening procedure. There is, however, a case to be made for women to become more “breast aware."Exactly same is our concept of BSE. We also want women to become more breast aware so as to diagnose the condition early [14].

In our study out of 56 malignant lesions, 52 were diagnosed as Ductal carcinoma (NOS). Goehring C et al reported that invasive ductal carcinoma is the commonest breast malignancy and found in the age group of 41-60 years of age [8]. In our study tissues were available for histological study in 123 cases (67 benign, 52 malignant \& 4 suspicious). So, considering histological diagnosis as the gold standard, we found that the sensitivity and specificity of FNAC to detect malignant cases was $98.2 \% \& 98.5 \%$ in our study.

With regard to women's attitudes toward BSE, the majority believed that it is not difficult and time consuming or troublesome $(63 \%$ and $72 \%$, respectively). Sixty-three percent of the respondents claimed that they know how to examine their breasts, but only $6 \%$ performed BSE monthly. The practice of BSE was significantly associated with age $(p=0.01)$, the level of education ( $p<0.0001)$, personal history of breast problems $(p<0.0001)$, and knowledge of how to examine the breasts $(p<0.0001)[15]$.

Knowledge regarding self breast examination plays a key role. Proper intervention through training programmes at regular time interval has global practices. Training not only increase knowledge and awareness among general population, but also develops sense of responsibility which reflects in their attitude and practices [16].

\section{Conclusion}

Knowledge and behaviors of female health care workers concerning breast cancer is relatively poor and it needs to be improved. Considering the role that health care workers may play in communicating health behaviors to the general public, planning health education interventions for this group of females is essential. Benign breast lesions constitute a majority of breast lumps in surgical cases and mainly occur in second and third decade. Fibroadenoma, fibrocystic change and mastitis forms the major bulk of benign breast lumps. In our study FNAC provided highly efficient preoperative diagnosis in breast lesions thus is an important denominator for planning of management. Its use in detecting the presence of cancer before surgery and as a guide to rational treatment has been well documented. So BSE is an inexpensive but efficient tool to make females more breasts aware.

Funding: Nil, Conflict of interest: None initiated Permission from IRB: Yes

\section{References}


1. Khanzada TW, Samad A, Sushel C. Spectrum of benign breast diseases. Pak J Med Sci. 2009 Apr $1 ; 25(2): 265-8$.

2. Agarwal G, Pradeep PV, Aggarwal V, Yip CH, Cheung PS. Spectrum of breast cancer in Asian women. World journal of surgery. 2007 May 1;31(5):1031-40.

3. Hisham AN, Yip CH. Spectrum of breast cancer in Malaysian women: overview. World J Surg. 2003 Aug;27(8):921-3. Epub 2003 Jun 6.

4. Leong SP, Shen ZZ, Liu TJ, Agarwal G, Tajima T, Paik NS, Sandelin K, Derossis A, Cody H, Foulkes WD. Is breast cancer the same disease in Asian and Western countries? World J Surg. 2010 Oct;34(10):2308-24. doi: 10.1007/s00268-010-0683-1.

5. Agarwal G, Ramakant P, Forgach ER, Rendón JC, Chaparro JM, Basurto CS, Margaritoni M. Breast cancer care in developing countries. World J Surg. 2009 Oct;33(10):2069-76. doi: 10.1007/s00268-009-0150-z.

6. Guray M, Sahin AA. Benign breast diseases: classification, diagnosis, and management. The oncologist. 2006 May 1;11(5):435-49.

7. Shukla HS, Kumar S. Benign breast disorders in nonwestern populations: Part II-benign breast disorders in India. World journal of surgery. 1989 Nov $1 ; 13(6): 746-9$.

8. Goehring C, Morabia A. Epidemiology of benign breast disease, with special attention to histologic types. Epidemiologic reviews. 1997 Jan 1;19(2):310-27.

9. Mackinnon WB, Barry PA, Malycha PL, Gillett DJ, Russell P, Lean CL, Doran ST, Barraclough BH, Bilous M, Mountford CE. Fine-needle biopsy specimens of benign breast lesions distinguished from invasive cancer ex vivo with proton MR spectroscopy. Radiology. 1997 Sep;204(3):661-6.
10. Thomas DB, Self SG, Allison CJ, Tao Y, Mahloch J, Ray R, Qin Q, Presley R, Porter P, Gao DL. Randomized trial of breast self-examination in Shanghai: methodology and preliminary results. Journal of the National Cancer Institute. 1997 Mar 5;89(5):35565.

11. Baxter N, Canadian Task Force on Preventive Health Care. Preventive health care, 2001 update: Should women be routinely taught breast selfexamination to screen for breast cancer?. Canadian Medical Association Journal. 2001 Jun 26;164(13):1837-46.

12. Foster Jr RS, Lang SP, Costanza MC, Worden JK, Haines CR, Yates JW. Breast self-examination practices and breast-cancer stage. New England Journal of Medicine. 1978 Aug 10;299(6):265-70.

13. Haji-Mahmoodi M, Montazeri A, Jarvandi S, Ebrahimi M, Haghighat S, Harirchi I. Breast Self-Examination: Knowledge, Attitudes, and Practices Among Female Health Care Workers in Tehran, Iran. The Breast Journal. 2002 Jul 1;8(4):222-5.

14. Austoker J. Cancer Prevention in Primary Care: Screening and self examination for breast cancer. BMJ. 1994 Jul 16;309(6948):168-74.

15. Minami Y, Ohuchi N, Taeda Y, Fukao A, Hisamichi S. Risk factors for benign breast disease according to histopathological type: comparisons with risk factors for breast cancer. Japanese journal of cancer research. 1998 Feb 1;89(2):116-23.

16. Carter CL, Corle DK, Micozzi MS, Schatzkin A, Taylor PR. A prospective study of the development of breast cancer in 16,692 women with benign breast disease. American journal of epidemiology. 1988 Sep $1 ; 128(3): 467-77$.

\section{How to cite this article?}

Brahmachari S, Sharma S, Pandey A. Spectrum of benign breast diseases \& role of self breast examination: a medical college experience in Madhya Pradesh. Int J Med Res Rev 2016;4(11):2077-2082.doi:10.17511/ijmrr. 2016.i11.30. 